\title{
Is Inflation a Monetary Phenomenon in the East European Economies? - Multifrequency Bayesian Quantile Inference
}

\author{
Dejan ŽIVKOV* - Jelena KOVAČEVIĆ** - Sanja LONČAR*
}

\begin{abstract}
This paper tries to determine how growth of money supply affects inflation in different time-horizons and under different inflation levels in the Czech Republic, Poland, Hungary and Russia. The research is done by using two innovative methodologies - the wavelet approach and Bayesian quantile regression. By observing these four countries, we can assess whether inflation targeting (IT) plays significant role in curbing inflation, because three Visegrad group countries adopted IT almost two decades ago, while Russia started to conduct IT relatively recently. Estimated quantiles suggest that money supply growth does not influence inflation in the Czech Republic and Hungary, whatsoever. We find that money growth impacts inflation in Poland, but very modestly. On the other hand, in the case of Russia, the transmission effect from money to inflation is much higher, and it goes around $40 \%$ in low inflation conditions, when M1 aggregate is observed, and around $78 \%$ in low inflation conditions, when M3 aggregate is analysed. The overall results clearly indicate that the adoption of the IT framework as a disinflation strategy proved to be successful in the Visegrad group countries, since excessive money growth has little or no effect at all on inflation in these countries.
\end{abstract}

Keywords: money, inflation, wavelet, Bayesian quantiles, Central and Eastern European countries

JEL Classification: C11, C21, E31, E51

DOI: https://doi.org/10.31577/ekoncas.2020.08.02

\footnotetext{
* Dejan ŽIVKOV - Sanja LONČAR, Novi Sad Business School, University of Novi Sad, Vladimira Perića Valtera 4, 21000 Novi Sad, Serbia; e-mail: dejanzivkov@gmail.com; Sanja. Loncar@vps.ns.ac.rs

** Jelena KOVAČEVIĆ, 'LEMIT' Company, Futoška 11, 21000 Novi Sad, Serbia; e-mail: jelenakovacevic.06@gmail.com
} 


\section{Introduction}

Understanding the connection between money and inflation is an enduring area of research in macroeconomics. In the context of the Keynesian-Monetarist debate of the 1970s, Friedman (1968) famously claimed that "inflation is always and everywhere a monetary phenomenon". According to early studies, such as Pigou (1951), inflation changes with money supply in the same direction and proportion which confirms the perspective of the traditional quantity theory of money (QTM). This theory proposes that relationship between money supply growth and inflation is unity in the long-run, whereby this nexus is based on purely monetary forces. According to Budina et al. (2006), high inflation cannot persist unless it is caused by an excessive money creation, while Nelson (2008) asserted that money provides useful information for monetary policy. On the other hand, Duczynski (2005), Telatar and Cavusoglu (2005) and Horvath, Komarek and Rozsypal (2011) claimed that the role of money in monetary policy conduct has been greatly disputed in recent years, thus a further evidence is needed.

This paper tries to contribute to the literature by investigating the causal relationship between money supply growth and inflation in four Central and Eastern European countries (CEEC). Three of them are the members of the Visegrad group, which kept monetary neutrality - the Czech Republic, Poland and Hungary, whereas the fourth one is Russia. We decided to analyse these markets because the selected countries have many common features. In other words, they jointly underwent a transition to a market economy, which produced similar changes in both price-setting and inflation expectations. Due to dramatic structural changes, these countries have a major challenge to understand the true nature of inflation (see Baranowski and Malaczewski, 2016; Gajewski, 2018). In addition, according to the OECD statistics, narrow money (M1 aggregate) has grown 7.7, 20.1, 24.3 and 178.3 times in the period between 1995 - 2018 in the Czech Republic, Poland, Hungary and Russia, respectively. Figure 1 depicts outstanding money growth in the selected countries in the period between $1995-2018$.

Fig u re 1

Monthly Index Growth Path of Narrow and Broad Money of the Selected CEEC
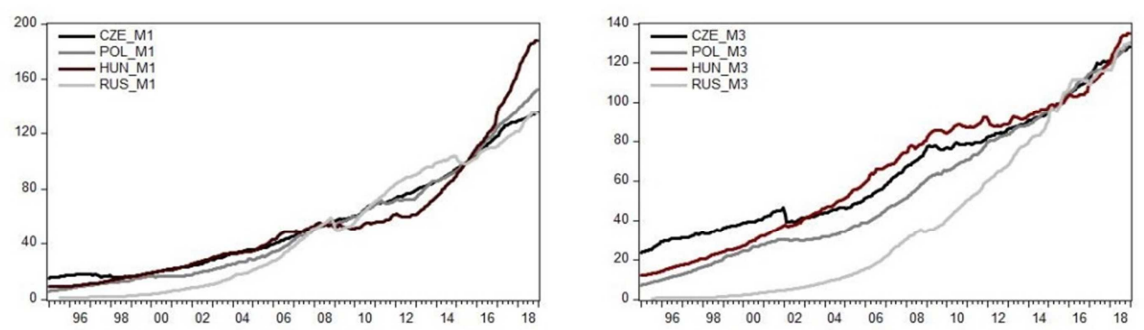

Source: Authors' calculation. 
Oomes and Ohnsorge (2005) explained why Russia has such tremendous money growth. They asserted that Central bank of Russia (CRB) has been fighting pressures for rouble appreciation due to recovery of oil and metals prices since 2000, which is accompanied by current account surpluses in Russia. In that effort, CBR has conducted non-sterilized foreign exchange purchases, which resulted in rapid growth of monetary aggregates. Also, it should be said that the selected Visegrad group countries pursue prudent anti-inflationary policy, and in that sense, they introduced inflation targeting (IT), as a disinflation strategy, two decades ago in roughly the same time - the Czech Republic in December 1997, Poland in September 1999, and Hungary in June 2001. On the other hand, Russia adopted IT strategy much later, in a wake of huge oil price crisis in January 2014. This timediscrepancy in IT introduction between Russia and the Visegrad group countries gives us an opportunity to test how rapid money growth affects inflation in two different conditions, i.e. when central bank is highly dedicated to keep inflation low via IT strategy (Visegrad group countries) and when central bank pursue a relatively non-ambitious disinflation path (Russia). Figure 2 shows empirical dynamics of inflation for the selected countries, where vertical line indicates the month in which IT strategy was implemented. As can be seen, all Visegrad countries adopted IT at the beginning of our sample, while Russia did it at the end of the sample. Due to the fact that majority of sample for Visegrad countries is under IT regime, whereas the Russian sample is not under IT in the most part, we can test the validity of the traditional QTM in two different systems.

Fig u r e 2

\section{Empirical Dynamics of Deseasonalized Inflation for the Selected Countries}
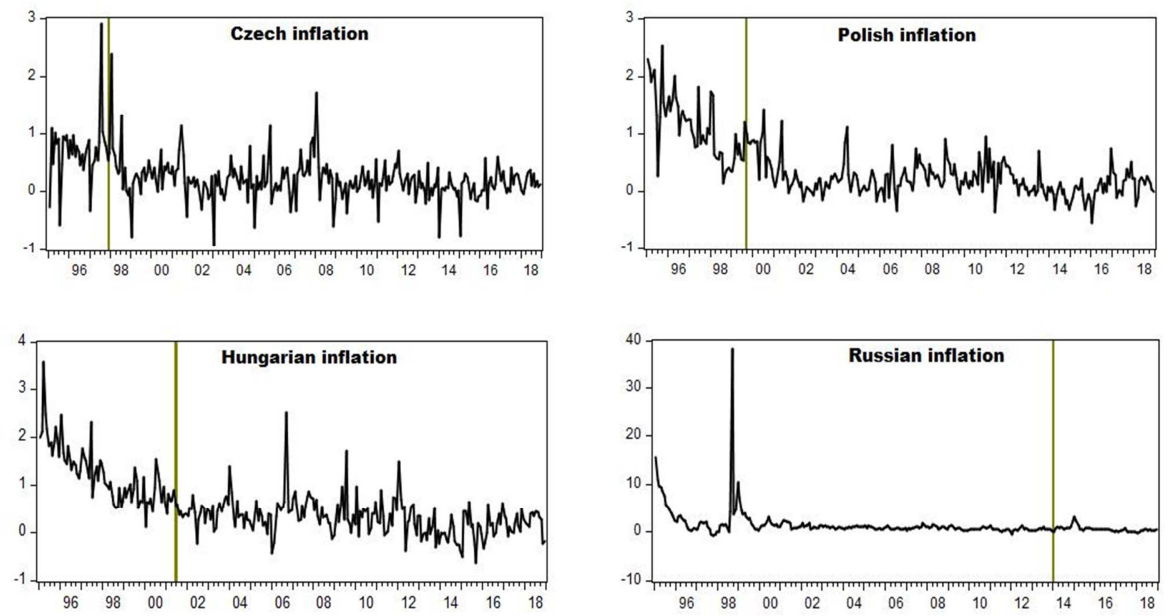

Note: Vertical line indicates the period when IT strategy was implemented.

Source: Authors' calculation. 
Having in mind aforementioned, we perform a thorough analysis on the selected CEEC, taking into account different time horizons (short-term, midterm and long term) and different levels of inflation (low, moderate and high). The idea to do research in this way is related to the papers of Rua (2012) and De Grauwe and Polan (2005). The former author claimed that money growth and inflation can vary across different time-horizons, while the latter authors asserted that the strong link between inflation and money growth is present in high-inflation countries, but this nexus in low-inflation countries is weak. To be more detailed in the analysis, the money supply in this study is observed by two different theoretic monetary aggregates - narrow money (M1) and broad money (M3). In order to find a credible answer on the question in which extent the inflation movements can be explained by a growing money supply, we combine two innovative, non-traditional methodologies that has been relatively recently developed - wavelet signal decomposing method and Bayesian quantile regression. Different time-horizons are observed by using three wavelet scale-signals, while the accurate measurement of these effects in different market conditions is estimated via the Bayesian quantile regression.

Wavelet methodology has many appealing characteristics. For instance, Dewandaru et al. (2014) highlighted that wavelet analysis has significant advantage over the well-known Fourier analysis, especially when time series are non-stationary or locally stationary. Dajčman (2012) explained that wavelets are powerful signal-processing tool, which can decompose the time-frequency relationships between observed variables and help researchers to grasp whether the relationship varies across frequencies and evolves over time. In other words, this model-free approach enables researchers to stipulate the dynamic dependence at different time-horizons, while it overcomes the problem of sample size reduction and loss of valuable information at the same time. From our perspective, wavelet methodology is useful in providing an answer for monetary policy-makers how money supply affects high, medium and low frequency variations of inflation. Numerous recent studies used wavelet methodology to study various economic phenomena in different time-horizons (see e.g. Barunik and Vacha, 2013; Kučerová and Poměnková 2015; Lee and Lee, 2016; Altar, Kubinschi and Barnea, 2017; Živkov, Balaban and Đuraškvić, 2018).

In addition, our goal is to gauge as accurately as possible the extent in which money supply affects inflation under different levels of inflation (low, moderate and high) in the selected countries. In that effort, we insert the decomposed wavelet signals into the Bayesian quantile regression $(\mathrm{QR})$ framework, which uses MCMC (Markov Chain Monte Carlo) in the estimation process, providing in that way an exact inference about the quantile parameters. This is the case 
because Bayesian QR technique decreases the length of the credible intervals and increases the accurateness of the quantile estimates in comparison with the traditional quantile regression approach of Koenker and Bassett (1978). We choose Bayesian quantile regression technique, because it can produce highly statistically significant parameters, even in low data setting, such as ours. ${ }^{1}$ Besides, quantile regression is a powerful tool in recognizing the deviations from normality and it gives reliable estimates in the extreme value environment. In other words, the usage of quantile regression in our research is justifiable because of the presence of outliers in the empirical inflation time-series, as Figure 2 indicates. Therefore, applying the wavelet-based Bayesian quantile methodology, we can address all aforementioned issues and acquire a reliable insight about the validity of traditional QTM in the selected countries. To the best of our knowledge, this paper is the first one to investigate thoroughly the influence of money growth on inflation in the selected CEEC, combining two innovative methodologies - the wavelet approach and Bayesian QR.

Besides introduction, the rest of the paper is structured as follows. Section 1 gives brief literature survey. Section 2 explains used methodologies - wavelet approach and Bayesian quantile regression. Section 3 presents dataset. Results of the estimated multiscale quantile parameters are contained in the fourth section. The last section offers concluding remarks.

\section{Brief Literature Survey}

Horvath, Komarek and Rozsypal (2011) asserted that the looming question is not so much whether money matters, but rather to what extent it matters. Various papers tested this contention, and this section briefly presents their findings. For instance, Budina et al. (2006) used the cointegration methodology to examine the equilibrium relations between real money, output and inflation in Romania, in the period between $1992-2000$. They reported that the three variables are linked in a cointegrating relation. Based on the results, they concluded that inflation was largely a monetary phenomenon in Romania. De Grauwe and Polan (2005) considered a sample of 160 countries in order to test the quantity theory relationship between money and inflation. They found a significant positive relation between long-run inflation and the money growth rate, but this nexus is not proportional. They asserted that the strong link between inflation and money growth is present in high-inflation countries in the sample. On the other hand, the link between inflation and money growth for low-inflation countries is weak.

\footnotetext{
${ }^{1}$ A total number of montly observations for the Visergrad countries is 288 , whereas this number for Russia is 282 .
} 
Thornton (2008) examined the long-run money-inflation relation for 36 African countries using cross-section and panel data analysis and reached similar conclusion as De Grauwe and Polan (2005). He claimed that strong positive link between money and inflation is typically inherent to high-inflation countries. Also, he found weak long-run relation between money growth and inflation when money growth and inflation are below 10\%. Hall et al. (2009) researched the causal relationship between money and price for the euro area using quarterly data for the period $1980-2006$. They found a bidirectional causal relationship between money and prices.

Canova and Menz (2010) studied whether money play statistically and economically significant role for cyclical fluctuations of output and inflation in Japan. They argued that money is important for inflation determination both directly, through the Phillips curve, and indirectly, through the Central Bank determination of the nominal interest rate. Rua (2012) researched the relationship between money growth and inflation in the euro area, but he observed the validity of QTM in different time horizons. His findings indicated that stronger link between inflation and money growth is present in shorter time horizons. Paul, Rather and Ramachandran (2017) compared the performance of traditional Phillips curve approach against the P-star model in order to examine the role of money in explaining inflation in India. They concluded that the P-star model with real money gap has an advantage over traditional Phillips curve in forecasting inflation. In addition, they contended that the changes in real money gap play a crucial role in explaining inflation in India. Makin, Robson and Ratnasiri (2017) investigated the connection between money supply (M3 aggregate) and inflation in Australia in the period $1970-1915$. They determined that excess money growth has been the main cause of Australia's inflation, although it became less important during the inflation targeting era.

\section{Research Methodologies}

\subsection{Wavelet Approach}

We try to investigate how/whether money impact inflation in different timehorizons in the selected CEEC. In that process, we consider a two-step waveletbased Bayesian quantile regression procedure. In the first step, we transform the empirical time-series in the several wavelet time-frequency signals. In particular, wavelet technique can decompose time-series into their time-frequency components, allowing researchers to study whichever economic phenomenon in different time-horizons. Nikkinen et al. (2011), Madaleno and Pinho (2012) claimed that 
wavelets can provide an appropriate trade-off between resolution in the time and frequency domains, which traditional Fourier analysis cannot do. Wavelet theory knows two key wavelet functions: the father wavelet $(\phi)$ and the mother wavelet $(\psi)$ (see e.g. Živkov, Manić and Đurašković, 2019; Wang and Li, 2020). Father wavelets augment the representation of the smooth or low frequency parts of a signal with an integral equal to 1 , whereas the mother wavelets can describe the details of high frequency components with an integral equal to 0 . In other words, father wavelet describes the long-term trend over the scale of the time series, while the mother wavelet delineates fluctuations in the trend. The functions of father wavelet $\phi_{J, k}(t)$ and mother wavelet $\psi_{j, k}(t)$ are generated as in equation (1):

$$
\phi_{J, k}(t)=2^{-J / 2} \phi\left(\frac{t-2^{J} k}{2^{J}}\right), \quad \psi_{j, k}(t)=2^{-j / 2} \psi\left(\frac{t-2^{j} k}{2^{j}}\right)
$$

For our research, we utilize the maximum overlap discrete wavelet transformation (MODWT) algorithm, ${ }^{2}$ which is based on a highly redundant non-orthogonal transformation. In that sense, a signal-decomposing procedure in MODWT is given in the following way:

$$
\begin{gathered}
S_{J}(t)=\sum_{k} S_{J, k} \phi_{J, k}(t) \\
D_{j}(t)=\sum_{k} D_{j, k} \psi_{j, k}(t) \quad j=1,2, \ldots, J
\end{gathered}
$$

where symbols $S_{J}(t)$ and $D_{j}(t)$ stand for the fluctuation and scaling coefficients, respectively, at the $\mathrm{j}$-th level wavelet that reconstructs the signal in terms of a specific frequency (trending and fluctuation components). Accordingly, an empirical time series $y(t)$ can be expressed in terms of those signals as:

$$
y(t)=S_{J}(t)+D_{J}(t)+D_{J-1}(t)+\ldots+D_{1}(t)
$$

\subsection{Bayesian Quantile Regression}

After the construction of the several wavelet signals via MODWT procedure, we embed those signals in the Bayesian quantile regression framework. ${ }^{3}$ Quantile regression $(\mathrm{QR})$ methodology was originally introduced by Koenker and Bassett (1978), and this technique extends the mean regression model to conditional quantiles of the response variable. This approach provides a more detailed view of the relationship of the dependent variable and the covariates, because it can

\footnotetext{
${ }^{2}$ Wavelet transformation was done via 'waveslim' package in ' $R$ ' software.

${ }^{3}$ Bayesian quantile parameters were calculated via 'bayesQR' package in ' $R$ ' software.
} 
estimate how a set of covariates affect the different parts of the distribution of regressand. Also, according to Benoit and van den Poel (2012), parameter estimates of QR are not biased by a location-scale shift of the conditional distribution of the dependent variable. This particular characteristic of QR has been found appealing by many researchers from various theoretical disciplines (see e.g. Maestri, 2013; Dybczak and Galuščák, 2013; Vilerts, 2018; He, Xu and Men, 2020).

In order to explain the Bayesian QR methodology, we start with the standard linear model as in equation (5):

$$
y_{i}=\mu\left(x_{i}\right)+\varepsilon_{i}
$$

where dependent variable $y_{i}$ is inflation, while $x_{i}$ can be either narrow money (M1) or broad money (M3) aggregate. According to Benoit and van den Poel (2017), if $\operatorname{Med}(\varepsilon \mid x)=0$ is assumed, then $\mu\left(x_{i}\right)$ is a conditional median func-

tion, while a linear conditional median model is given by $\operatorname{Med}\left(y_{i} \mid x_{i}\right)=x_{i} \beta$. According to these authors, the regression coefficient can be found by solving equation (6):

$$
\operatorname{argmin} \sum_{i=1}^{n}\left|y_{i}-x_{i} \beta\right| ; \beta \in \mathfrak{R}
$$

Quantile regression extends the median case to all other quantiles, and these quantile parameters can be estimated by the following equation:

$$
\hat{\beta}(\tau)=\operatorname{argmin} \sum_{i=1}^{n} \rho_{\tau}\left(y_{i}-x_{i} \beta\right) ; \beta \in \mathfrak{R}
$$

where $\tau \in(0,1)$ is any quantile of interest, while $\rho_{\tau}(z)=z(\tau-I(z<0))$ and $I($. stands for the indicator function. The quantile $\hat{\beta}(\tau)$ is called the $\tau^{\text {th }}$ regression quantile, while in the case where $\tau=0.5$, it corresponds to median regression. Benoit and van den Poel (2012) explained that Koenker and Machado (1999) found that likelihood-based inference, which uses independently distributed asymmetric Laplace densities (ALD), is directly linked to the minimization problem in equation (7). This finding was a starting point for $\mathrm{Yu}$ and Moyeed (2001) to commence the development of the Bayesian-based quantile regression. $\mathrm{Yu}$ and Zhang (2005) proposed a three-parameter ALD with the skewness parameter that can be used directly to model the quantile of interest, as equation (8) suggests:

$$
(y \mid \mu, \sigma, \tau)=\frac{\tau(1-\tau)}{\sigma} \exp \left\{-\rho_{\tau}\left(\frac{y-\mu}{\sigma}\right)\right\}
$$


where

$$
\rho_{\tau}(y)=y(\tau-I(y<0))
$$

Benoit and van den Poel (2012) contended that equation (9) is identical to the loss function in the optimization problem in equation (7). Therefore, according to these authors, minimizing equation (7) is equivalent to maximizing a regression likelihood using ALD errors with $\mu=x_{i} \beta$. First step of the implementation of the Bayesian quantile regression involves the formation of a likelihood, which involves the independent asymmetric Laplace densities with $\mu=x_{i} \beta$, specifying the quantile of interest $(\tau)$, and placing priors on the model parameters $\beta$ and $\sigma$. The model parameters are then estimated by conventional Bayesian procedure, which implies the usage of the MCMC algorithm (Markov Chain Monte Carlo), which produces exact estimates of the quantile parameters $\hat{\beta}(\tau)$. Sriram, Ramamoorthi and Ghosh (2012) asserted that crucial advantage of the Bayesian quantile regression comparing to the conventional $\mathrm{QR}$ approach is the fact that $95 \%$ Bayesian credible interval contains the true parameter value $95 \%$ of the time. These authors also claimed that with increasing sample size, coverage improves and the length of the credible intervals decreases. This implies that quantile parameters, which are estimated with traditional OLS and MCMC estimator, would probably be different in the magnitude as well as in the statistical significance. We want to test this assertion, and for that cause, we estimate QR parameters in both ways, i.e. with OLS and MCMC procedures. These results are presented in the fifth section.

\section{Dataset and Preliminary Analysis}

Dataset used for this study comprises monthly index data of monetary aggregates M1 and M3 as well as consumer price index (CPI) of four Central and Eastern European Countries - the Czech Republic, Poland, Hungary and Russia. All indices are transformed into natural logarithms, according to the expression: $r_{i, t}=100 \times\left(P_{i, t} / P_{i, t-1}\right)$, where $P_{i, t}$ stands for the selected indices. In other words, all the time-series are observed as growth rates. The sample ranges from January 1995 to December 2018 for Visegrad group countries and from July 1995 to December 2018 for Russia due to unavailability of the empirical data before July 1995. Monthly data indices for monetary aggregates are collected from the OECD statistics, while CPI indices are retrieved from the IMF World Economic Outlook database. Before wavelet transformation, we seasonally adjust all time-series, using filter-based methods of seasonal adjustment, known as X11 style method. 
Figure 3

Wavelet Details of the Czech Inflation and Monetary Aggregates M1 and M3
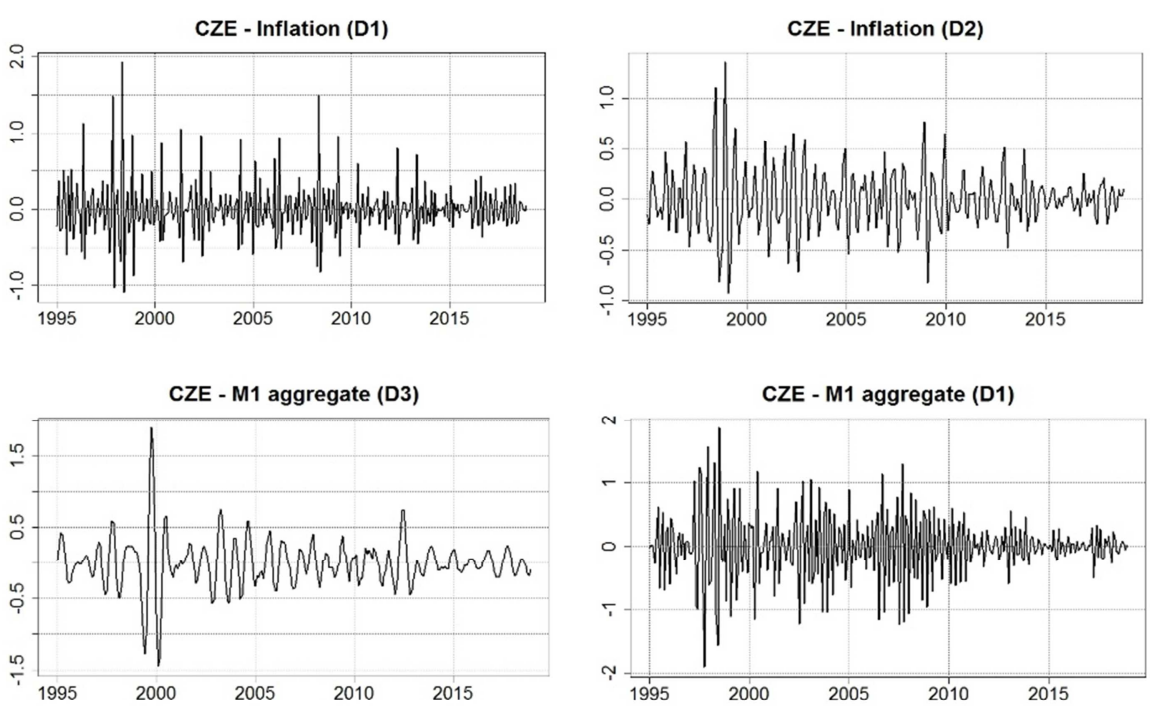

CZE - M1 aggregate (D2)
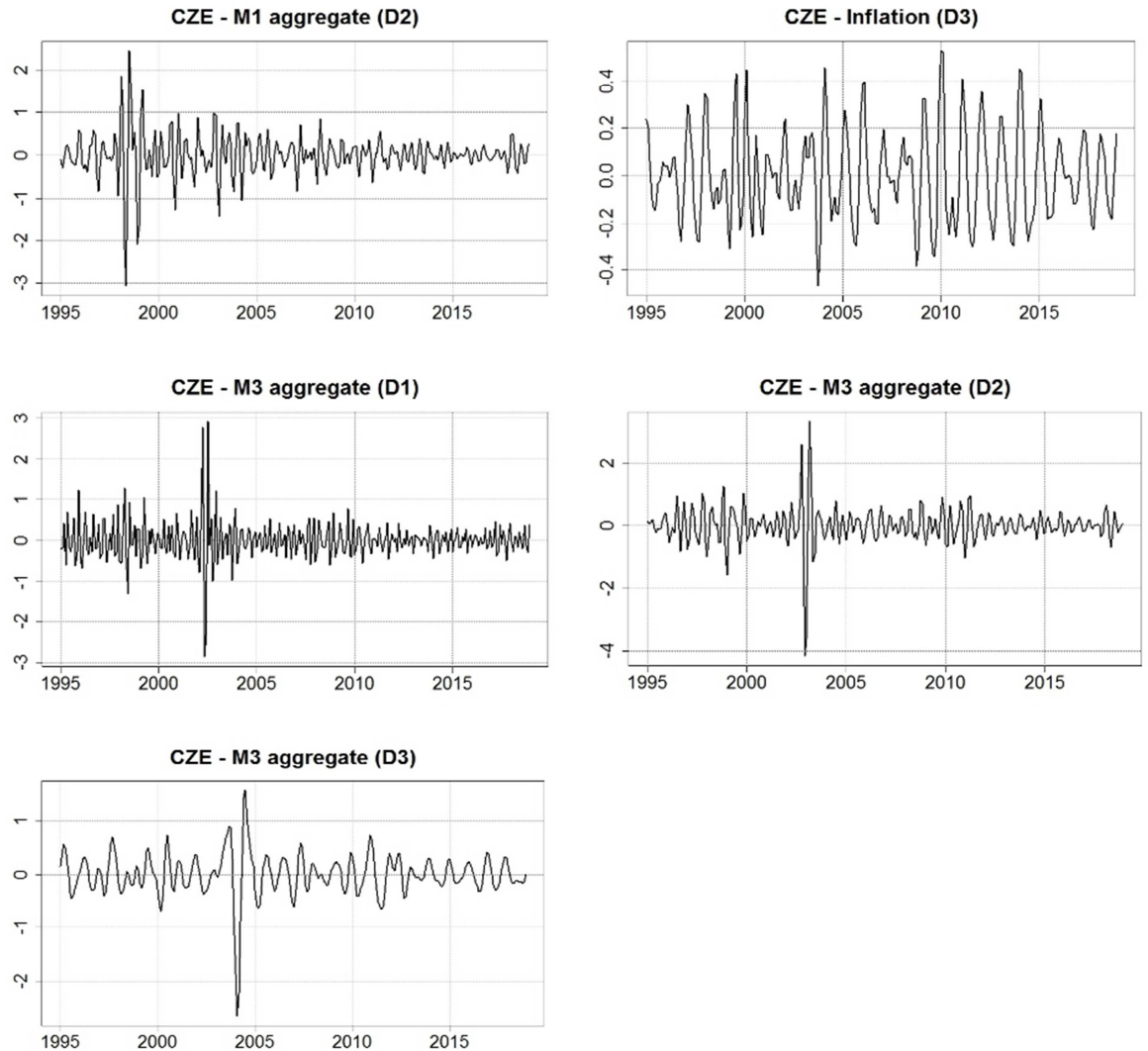

Source: Authors' calculation. 
In order to perform the assessment of QTM validity in different time horizons, we transform all empirical time-series in three wavelet scales. First scale corresponds to the short time-horizon ( $2-4$ quarters), second scale is treated as midterm horizon ( $4-8$ quarters), while third scale observes the long-term horizon ( 8 - 16 quarters).

In order to preserve space, we present three wavelet scales of M1, M3 and inflation of the Czech Republic in Figure 3, while all other wavelet decomposed series can be obtained by request. As can be seen in Figure 3, all wavelet timeseries contain outliers and heavy tails, which means that our wavelet-based Bayesian QR approach is appropriate to tackle these features. This is the case because the wavelet method successfully deals with extreme movements and outliers in empirical signals (see Ahroum and Achchab, in press), while QR estimators are robust to deviations from normality and it performs very well in extreme value environment.

Table 1 contains descriptive statistics of quarterly growth rates of monetary aggregates (M1 and M3) and inflation for all the selected countries. It is obvious that Russia has the largest money growth rates, while the average rate of inflation is also the highest in Russia. Standard deviations indicate to erratic dynamics of the majority of the selected time-series, and this feature is the highest in the cases of Russia for all the selected time-series. All kurtosis values are higher than benchmark value of 3, while in some cases, these values are particularly high. Due to high skewness and kurtosis values, Jarque-Bera test suggests nonnormality for majority of the selected time-series. Table 1 does not contain unit root tests, because we do our calculations with the wavelet decomposed series, which are stationary by default.

The reliability and validity of the estimated Bayesian QR parameter can be verified by the use of a visual inspection of the MCMC chains convergence, which signals the evolution of the MCMC draws over the iterations. For our research, we use 3000 iterations. Figure 4 displays the trace-plots of the MCMC chain of the median quantiles, $\hat{\beta}(\tau)=0.5$, for three wavelet scales, taking into account the transmission effect from M1 to inflation in the Czech Republic. All three trace-plots suggest a good performance, which means that the effect of the initial values of the MCMC chains wears off very fast, while the MCMC sampler quickly moves to the stationary distribution. These findings give us an assurance about the trustworthiness of the estimated median Bayesian quantile parameters. Due to space parsimony and the fact that all other trace-plots are very similar across all quantiles, we present in Figure 4 only trace-plots for the Czech M1 aggregate in three wavelet scales, whereas all other trace-plots can be obtained by request. 
Table 1

Descriptive Statistics of Monthly Data for M1, M3 and Inflation

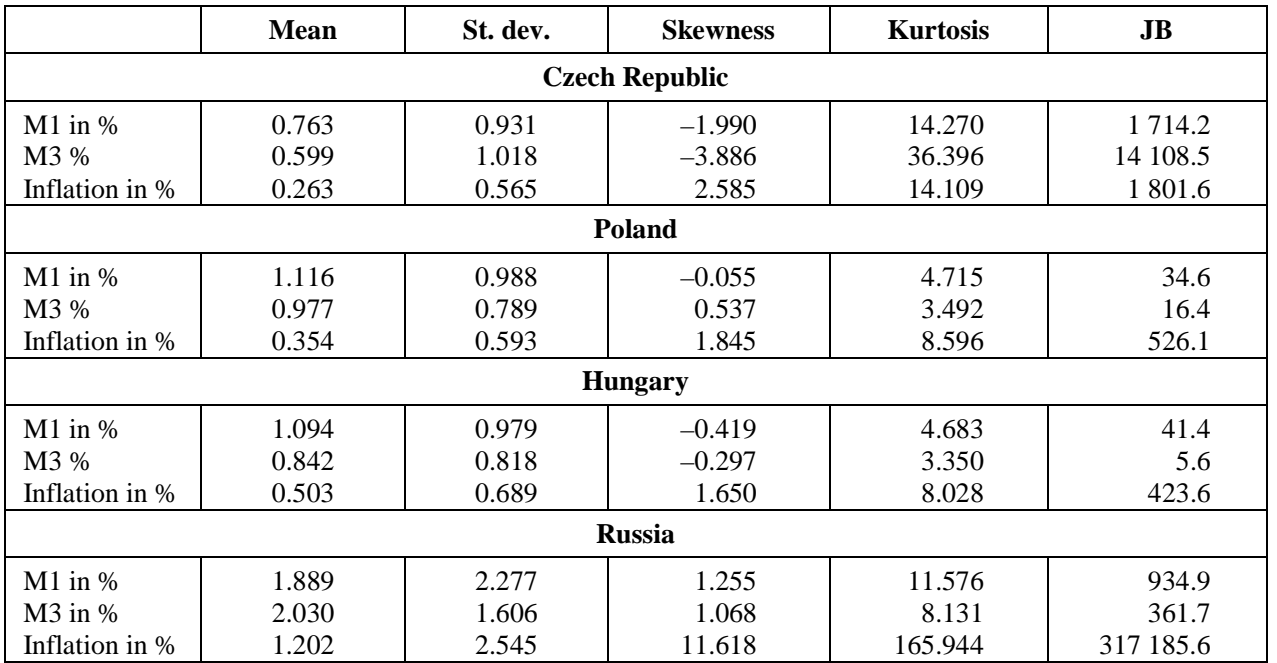

Note: JB stands for Jarque-Bera test of normality.

Source: Authors' calculation.

\section{Figure 4}

\section{Trace Plots for the Median Quantile of the Czech M1 Aggregate in Three Wavelet Scales}
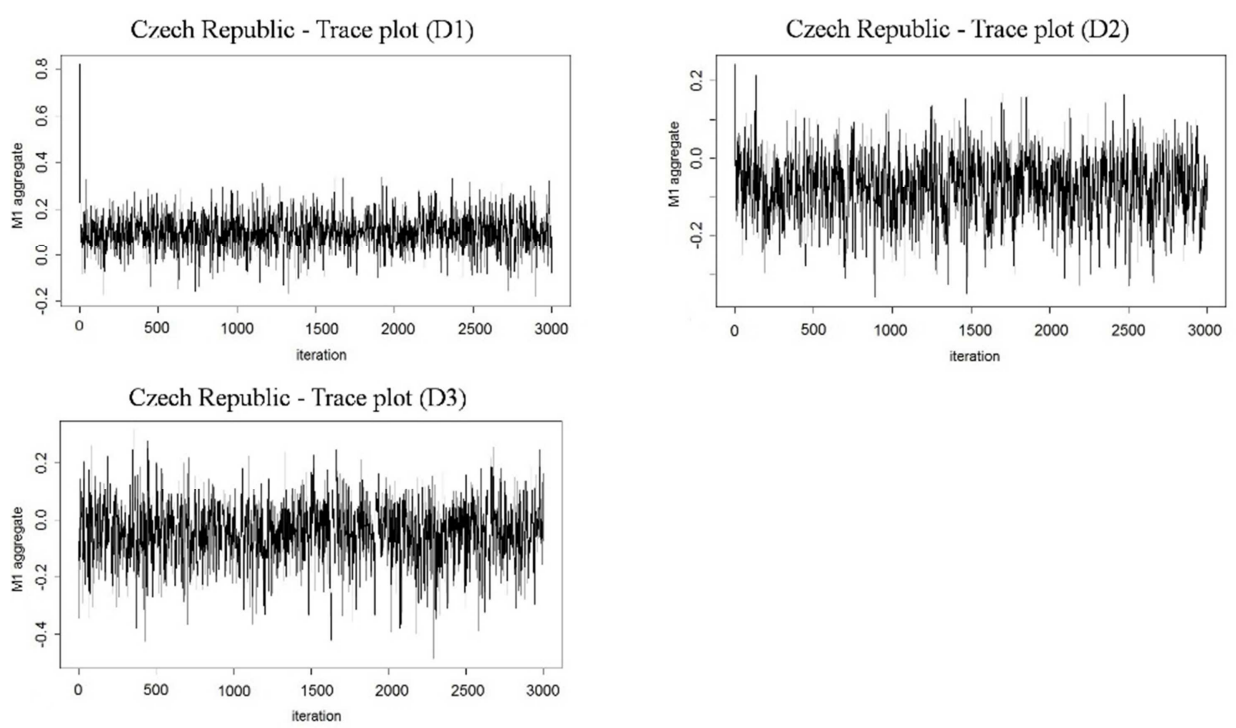

Note: The horizontal axis represents the number of MCMC iterations.

Source: Authors' calculation.

As a preliminary analysis, we calculate Granger causality test in order to see what classical and relatively simple methodology can tell us about the nexus, and these results can be compared later with more sophisticated approach - the 
wavelet-based Bayesian QR. Table 2 contains the results. Granger causality tests the hypothesis that M1 and M3 aggregates does not Granger cause inflation, while F-statistics and p-value suggest whether this hypothesis is confirmed or refuted. Taking into account that p-value under $10 \%$ means that hypothesis is refuted, it can be seen that the results are heterogeneous. For instance, in the case of the Czech Republic, Granger causality test indicates that M1 aggregate affects inflation only in midterm, whereas M3 aggregate has an effect on inflation in all three time-horizons. We find that M1 and M3 aggregates influence inflation only in long-term horizon, in the Polish case. In the Hungarian case, we do not find causality link between M1 and M3 aggregates and inflation, whatsoever. On the other hand, in the case of Russia, in four out of six instances, we find that money growth affect inflation. However, it should be said that Granger causality test can provide very limited information about the connection between money and inflation, since this method only can tell whether causal link exists between the two variables, without any indication about its magnitude. These results also need to be taken with great caution, because this methodology is very rudimental in its basis. Therefore, the next section presents the results of a very elaborate approach - wavelet-based Bayesian QR, which gives richer and more reliable results than Granger causality test.

T a b le 2

Granger Causality Test Between M1 and M3 Aggregates and Inflation

\begin{tabular}{|c|c|c|c|c|c|c|c|}
\hline Scale & Causality direction & F-statistics & p-value & Scale & Causality direction & F-statistics & p-value \\
\hline D1 & CZE: M1 $\rightarrow$ inf & 2.289 & 0.103 & D1 & POL: M1 $\rightarrow$ inf & 0.428 & 0.651 \\
D2 & CZE: M1 $\rightarrow$ inf & 4.211 & 0.016 & D2 & POL: M1 $\rightarrow$ inf & 1.461 & 0.234 \\
D3 & CZE: M1 $\rightarrow$ inf & 0.684 & 0.505 & D3 & POL: M1 $\rightarrow$ inf & 3.084 & 0.047 \\
D1 & CZE: M3 $\rightarrow$ inf & 7.544 & 0.001 & D1 & POL: M3 $\rightarrow$ inf & 0.177 & 0.838 \\
D2 & CZE: M3 $\rightarrow$ inf & 5.189 & 0.006 & D2 & POL: M3 $\rightarrow$ inf & 2.289 & 0.103 \\
D3 & CZE: M3 $\rightarrow$ inf & 3.000 & 0.051 & D3 & POL: M3 $\rightarrow$ inf & 3.706 & 0.025 \\
\hline D1 & HUN: M1 $\rightarrow$ inf & 1.567 & 0.210 & D1 & RUS: M1 $\rightarrow$ inf & 11.573 & 0.000 \\
D2 & HUN: M1 $\rightarrow$ inf & 0.073 & 0.930 & D2 & RUS: M1 $\rightarrow$ inf & 1.765 & 0.173 \\
D3 & HUN: M1 $\rightarrow$ inf & 0.097 & 0.907 & D3 & RUS: M1 $\rightarrow$ inf & 4.354 & 0.014 \\
D1 & HUN: M3 $\rightarrow$ inf & 0.380 & 0.684 & D1 & RUS: M3 $\rightarrow$ inf & 9.412 & 0.000 \\
D2 & HUN: M3 $\rightarrow$ inf & 0.591 & 0.554 & D2 & RUS: M3 $\rightarrow$ inf & 2.675 & 0.071 \\
D3 & HUN: M3 $\rightarrow$ inf & 0.694 & 0.500 & D3 & RUS: M3 $\rightarrow$ inf & 2.081 & 0.127 \\
\hline
\end{tabular}

Note: All Granger causality tests are performed with two lags.

Source: Authors' calculation.

\section{Empirical Results}

This section tries to answer how/whether money supply growth influences inflation in the selected CEECs in different time horizons and in different market conditions, i.e. in the cases when inflation is low, moderate and high. The results 
are presented via quantile parameters, which are estimated with both MCMC and OLS methods. Tables 3 and 4 contain these quantile estimates, regarding the transmission effect from M1 and M3 aggregates to inflation, respectively. As we have said previously, all quantile parameters estimated with MCMC algorithm are highly reliable and statistically significant, and this conclusion is drawn from the visual inspection of the trace plots, presented in the previous section. The results of MCMC quantile parameters are showed in Panel A in both Tables. On the other hand, we find mixed results in quantile regression results estimated with OLS method, in terms of their statistical significance. As a matter of fact, almost $50 \%$ of the QR parameters estimated with OLS are statistically insignificant in Table 3, while in Table 4, this percentage goes beyond 50\%. In addition, it is noticeable that the magnitude of the statistically significant OLS quantile parameters are higher than their MCMC counterparts. This suggests that MCMC method produces better results than OLS, and also give us a vindication for the Bayesian QR usage. Therefore, in the following, we comment only quantile parameters estimated with MCMC algorithm. A visual insight about the size of the estimated QR parameters via MCMC algorithm is presented in Figures 5 and 6.

As for the spillover effect from narrow money to inflation, it can be seen that estimated QR parameters bear both positive and negative signs in the selected CEEC. Negative signs indicate that growing money supply lowers inflation. In other words, it means that money supply does not affect inflation, whereby the presence of QTM tenet can be rejected. Table 3 suggests that negative QR parameters predominantly exist in the cases of the Czech Republic and Hungary, across the quantiles and wavelet scales. Bayesian quantile parameters are in line with Granger causality test for Hungary, and this adds to the robustness of the Hungarian results. However, this cannot be said for the Czech case, because Granger test suggests that money affect inflation. Therefore, we find a deviation between Granger and Bayesian QR results in the Czech case, but since Bayesian QR is more trustworthy method, we have to give more weight to the latter. On the other hand, the size of the estimated positive parameters in these two countries is really small, almost negligible. Therefore, the findings point out that excessive money growth in the Czech Republic and Hungary does not have an effect on inflation in these countries, whatsoever, and probable reason could be found in the fact that these countries are fully committed to conduct a prudent and responsible antiinflationary policy. This assertion stands in line with the fact that these countries have adopted IT strategy almost two decades ago and have conducted it relatively successfully ever since (see Erdős, 2008). According to some authors, IT moderates the level and volatility of inflation (Abo-Zaid and Tuzemen, 2012; Su et al., 2016), anchors inflation expectations (Blinder et al., 2008), and increases transparency and credibility of monetary policy (Babecký, Coricelli and Horváth, 2009). 
T a ble 3

Quantile Estimates for the Transmission Effect from M1 to Inflation

\begin{tabular}{|c|c|c|c|c|c|c|c|c|c|c|}
\hline \multirow{2}{*}{$\begin{array}{l}\text { Wavelet } \\
\text { details }\end{array}$} & \multicolumn{10}{|c|}{ Quantile estimates } \\
\hline & 0.05-th & 0.25 -th & 0.5 -th & 0.75 -th & 0.95-th & 0.05-th & 0.25 -th & 0.5 -th & 0.75 -th & 0.95-th \\
\hline \multicolumn{11}{|c|}{ Panel A: Quantile parameters estimated via MCMC algorithm } \\
\hline & \multicolumn{5}{|c|}{ Czech Republic } & \multicolumn{5}{|c|}{ Poland } \\
\hline D1 & -0.017 & 0.018 & 0.005 & -0.019 & -0.046 & 0.051 & 0.061 & 0.049 & 0.059 & 0.079 \\
\hline D2 & -0.082 & -0.092 & -0.088 & -0.096 & -0.097 & 0.065 & 0.047 & 0.032 & 0.024 & 0.013 \\
\hline \multirow[t]{2}{*}{ D3 } & -0.026 & -0.044 & -0.084 & -0.092 & -0.054 & 0.074 & 0.070 & 0.073 & 0.103 & 0.053 \\
\hline & \multicolumn{5}{|c|}{ Hungary } & \multicolumn{5}{|c|}{ Russia } \\
\hline D1 & 0.000 & 0.010 & -0.001 & -0.009 & -0.004 & 0.085 & 0.047 & 0.058 & 0.065 & 0.107 \\
\hline D2 & -0.005 & 0.004 & 0.007 & -0.014 & 0.006 & 0.187 & 0.056 & 0.036 & 0.031 & 0.084 \\
\hline D3 & -0.217 & -0.108 & -0.007 & -0.024 & -0.153 & 0.408 & 0.213 & 0.223 & 0.174 & 0.352 \\
\hline \multicolumn{11}{|c|}{ Panel B: Quantile parameters estimated via OLS } \\
\hline & \multicolumn{5}{|c|}{ Czech Republic } & \multicolumn{5}{|c|}{ Poland } \\
\hline D1 & $-0.079^{*}$ & 0.033 & -0.003 & -0.031 & -0.179 & $0.156^{* * *}$ & $0.100^{*}$ & $0.071^{*}$ & $0.097^{* *}$ & $0.212^{* * *}$ \\
\hline D2 & $-0.098^{* *}$ & $-0.156^{* * *}$ & -0.110 & $-0.124^{* * *}$ & $-0.074^{* *}$ & $0.159^{* * *}$ & 0.068 & $0.050^{*}$ & 0.026 & 0.033 \\
\hline \multirow[t]{2}{*}{ D3 } & 0.024 & $-0.053^{* * *}$ & $-0.125^{* * *}$ & $-0.166^{* * *}$ & -0.087 & -0.006 & 0.112 & $0.118^{*}$ & $0.166^{* * *}$ & $0.153^{*}$ \\
\hline & \multicolumn{5}{|c|}{ Hungary } & \multicolumn{5}{|c|}{ Russia } \\
\hline D1 & -0.051 & 0.037 & 0.032 & -0.0520 & 0.005 & $0.121^{* * *}$ & 0.012 & $0.084^{* *}$ & $0.095^{*}$ & $0.275^{* * *}$ \\
\hline D2 & -0.012 & -0.010 & 0.021 & -0.052 & 0.059 & $0.236^{* * *}$ & 0.054 & 0.026 & 0.034 & $0.126^{* * *}$ \\
\hline D3 & $-0.483^{\text {*** }}$ & $-0.196^{* *}$ & 0.021 & -0.067 & $-0.405^{* * *}$ & $0.538^{* * *}$ & $0.256^{* * * *}$ & $0.242^{*}$ & $0.200^{* * * *}$ & 0.347 \\
\hline
\end{tabular}

Note: ***p $<.01 ; * * \mathrm{p}<.05 ; * \mathrm{p}<.1$.

Source: Authors' calculation.

Our Bayesian QR results concur very well with the findings of some other authors, who studied inflation phenomenon in some CEEC, which adopted inflation targeting policy. For instance, Baxa, Plašil and Vašíček (2015) reported that intrinsic inflation persistence decreased substantially in the Czech Republic a few years after the adoption of inflation targeting in this country. Besides, Horvath (2008) asserted that inflation target is a major determinant of inflation expectations in the Czech Republic, and these inflation expectations decrease notably in response to stricter monetary policy and lower inflation target in the Czech Republic. Also, Ouyang and Rajan (2019) investigated 54 developing economies over the period 1980 and 2015 and claimed that IT frameworks clearly reduced inflation rates in developing economies regardless of the level of financial development. On the other hand, our results do not coincide to some degree with the assertion of Baxa, Plašil and Vašíček (2015). They contended that inflation targeting has relatively low impact on inflation dynamics in Hungary, while our results indicate that money supply growth does not have any impact on inflation in Hungary, since QR parameters are either negative or very low. However, the claim of Baxa, Plašil and Vašíček (2015) was focused on significant inflation persistence in Hungary, where they found that past inflation bears relevant information for the formation of inflation expectations. They offered an explanation that this could be associated with the significant role of the exchange rate in the Hungarian monetary policy. 
Figure 5

Plots of the Estimated Bayesian QR Parameters - The Transmission from M1 to Inflation
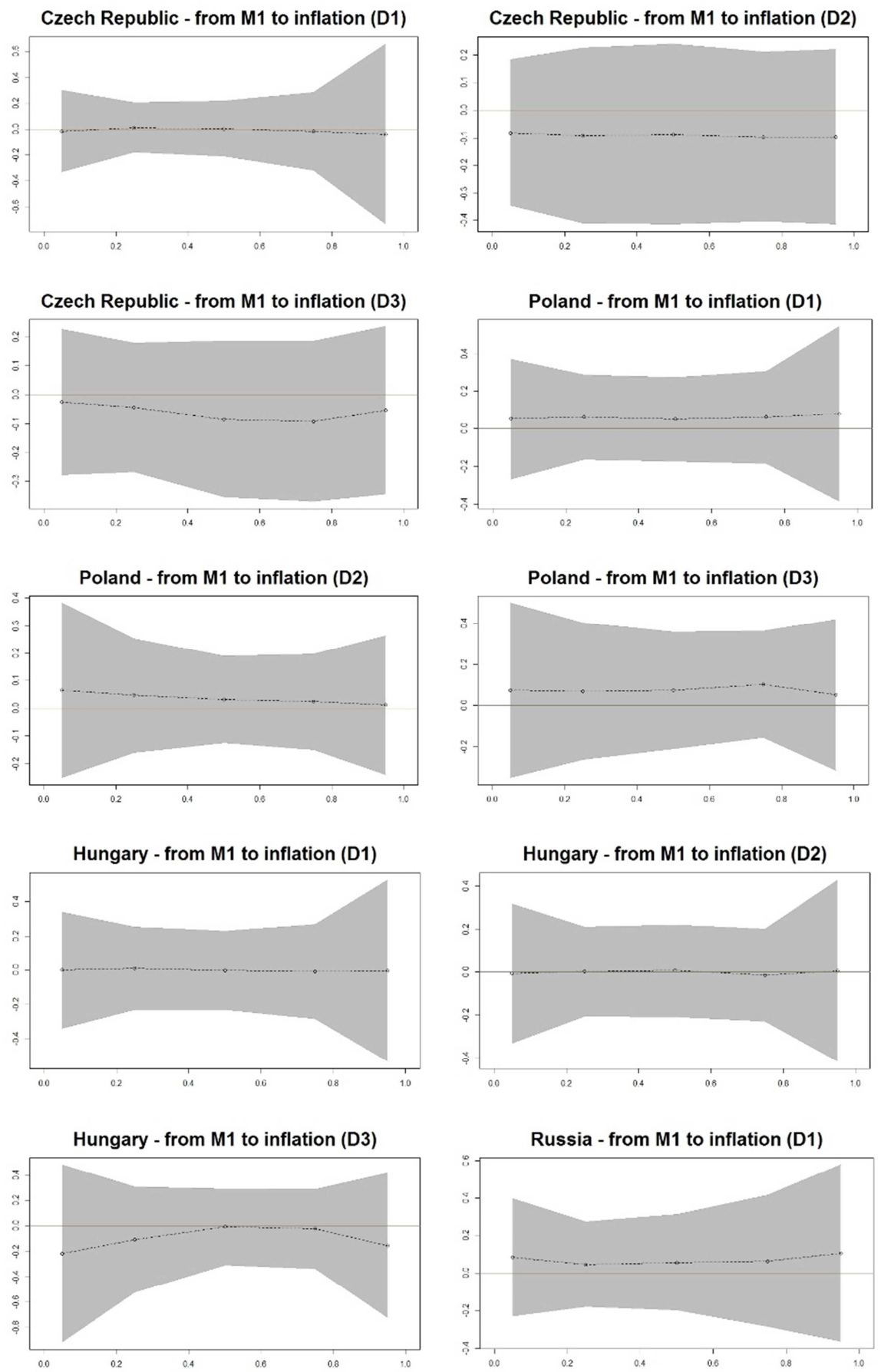

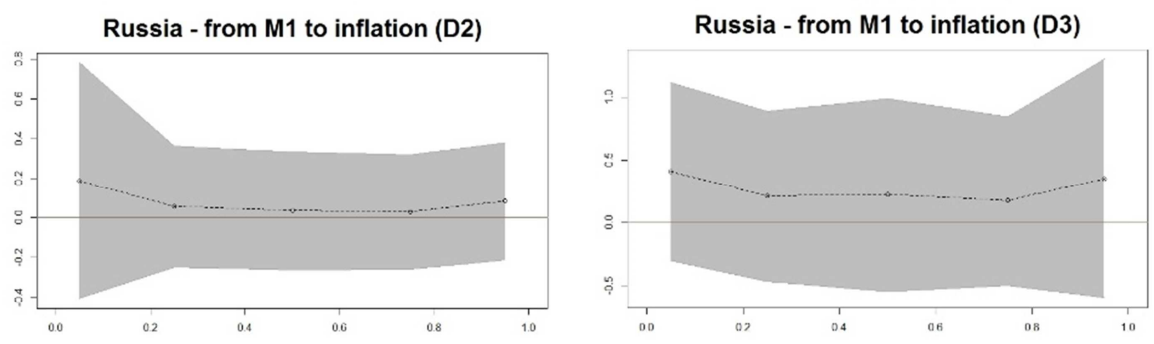

Note: The shaded area indicates credible intervals at 95 percent probability.

Source: Authors' calculation.

Contrary to the Czech and Hungarian results, we find positive Bayesian QR parameters in the cases of Poland and Russia, across the quantiles and wavelet scales. Also, it is noticeable that QR parameters in the third wavelet scale (the longest time-horizon) are the highest in both countries. These results are in line with Granger causality test in D3 scale for Poland and Russia, because this test clearly indicates that M1 aggregate affects inflation in the long-term horizon. The findings coincide with the traditional QTM to some extent, since this theory is in a position that relationship between money growth and inflation is unity in the long-run. However, our findings are far from this perfect connection, and they rather suggest that narrow money have relatively modest influence on inflation in Poland and significantly higher impact in Russia, but it is not one to one ratio at all. More specifically, the results show that the highest spillover effect from money to inflation in the longest time-horizon goes around $10 \%$ in the case of Poland in $75^{\text {th }}$ quantile. Poland adopted IT in 1999, and committed itself to pursue prudent anti-inflationary policy, but unlike the Czech and Hungarian cases, we find that money growth affects inflation in some degree. Our results are in line with the findings of de Mendonc (2018). This author researched Poland and six other emerging markets and asserted that only adopting inflation targeting is insufficient to anchor inflation expectations. She explained that Poland is in the group of countries which lacks of commitment to target inflation, and this generates inflation expectations that are determined by past inflation in large measure.

On the other hand, in the case of Russia, the Bayesian QR parameters are the highest in the long-term, in comparison with the short-term and midterm horizons. This effect is significantly higher in comparison to the Polish case, but yet again, this nexus is far from the perfect unity. We record the highest Bayesian QR parameters in the tails of the distribution, i.e. the spillover effect is around $40 \%$ in conditions when Russian inflation rate is exceptionally low, while this 
effect is around $35 \%$ when inflation rate is exceptionally high. When inflation rate is moderate, the spillover effect goes around $20 \%$.

T a ble 4

Bayesian Quantile Estimates for the Transmission Effect grom M3 to Inflation

\begin{tabular}{|c|c|c|c|c|c|c|c|c|c|c|}
\hline \multirow{2}{*}{$\begin{array}{l}\text { Wavelet } \\
\text { details }\end{array}$} & \multicolumn{10}{|c|}{ Quantile estimates } \\
\hline & 0.05-th & 0.25 -th & $0.5-$ th & 0.75-th & 0.95-th & 0.05 -th & 0.25 -th & 0.5 -th & 0.75-th & 0.95-th \\
\hline \multicolumn{11}{|c|}{ Panel A: Quantile parameters estimated via MCMC algorithm } \\
\hline & \multicolumn{5}{|c|}{ Czech Republic } & \multicolumn{5}{|c|}{ Poland } \\
\hline D1 & -0.005 & -0.019 & -0.056 & -0.125 & -0.128 & 0.072 & 0.046 & 0.042 & 0.054 & 0.095 \\
\hline D2 & 0.025 & -0.001 & 0.008 & 0.008 & -0.014 & 0.104 & 0.067 & 0.054 & 0.033 & 0.037 \\
\hline \multirow[t]{2}{*}{ D3 } & -0.014 & -0.009 & -0.006 & -0.025 & -0.046 & 0.112 & 0.074 & 0.063 & 0.093 & 0.163 \\
\hline & \multicolumn{5}{|c|}{ Hungary } & \multicolumn{5}{|c|}{ Russia } \\
\hline D1 & 0.021 & 0.005 & 0.006 & -0.010 & -0.094 & 0.308 & 0.095 & 0.109 & 0.165 & 0.449 \\
\hline D2 & -0.036 & 0.002 & -0.003 & -0.021 & -0.056 & 0.313 & 0.090 & 0.027 & 0.031 & 0.219 \\
\hline D3 & -0.038 & -0.057 & -0.016 & -0.046 & -0.094 & 0.780 & 0.203 & 0.174 & 0.186 & 0.609 \\
\hline \multicolumn{11}{|c|}{ Panel B: Quantile parameters estimated via OLS } \\
\hline & \multicolumn{5}{|c|}{ Czech Republic } & \multicolumn{5}{|c|}{ Poland } \\
\hline D1 & 0.033 & -0.014 & -0.069 & $-0.212^{* * *}$ & $-0.230^{* *}$ & $0.278^{* *}$ & 0.090 & 0.076 & 0.064 & 0.129 \\
\hline D2 & $0.082^{* *}$ & -0.003 & 0.003 & 0.018 & -0.020 & 0.269 & $0.095^{*}$ & $0.085^{*}$ & $0.069^{*}$ & 0.052 \\
\hline \multirow[t]{2}{*}{ D3 } & -0.005 & -0.023 & -0.021 & -0.070 & -0.047 & $0.304^{* * *}$ & $0.209^{*}$ & 0.105 & $0.201^{* * * *}$ & $0.375^{* *}$ \\
\hline & \multicolumn{5}{|c|}{ Hungary } & \multicolumn{5}{|c|}{ Russia } \\
\hline D1 & 0.044 & 0.032 & 0.042 & -0.063 & -0.183 & $0.400^{* * *}$ & 0.141 & $0.121^{*}$ & $0.176^{\text {**** }}$ & 0.594 \\
\hline D2 & -0.100 & 0.041 & -0.004 & -0.036 & -0.154 & $0.420^{* *}$ & $0.138^{*}$ & 0.021 & 0.064 & $0.309^{* * *}$ \\
\hline D3 & -0.010 & -0.144 & -0.037 & -0.099 & $-0.303^{* *}$ & $1.183^{* * *}$ & $0.261^{* * *}$ & $0.187^{* *}$ & $0.284^{* *}$ & $0.676^{* * *}$ \\
\hline
\end{tabular}

Note: $* * * \mathrm{p}<.01 ; * * \mathrm{p}<.05 ; * \mathrm{p}<.1$.

Source: Authors' calculation.

As for the transmission effect from M3 to inflation, the results are very similar with the results in Table 3, in a sense that the spillover effect is not found in the Czech Republic and Hungary, while in the cases of Poland and Russia, this effect exists, with the different magnitudes between Poland and Russia. These results are presented in Table 4, while the graphical illustration of the estimated Bayesian quantile parameters is contained in Figure 6. According to the results in Table 4, the validity of QTM principle is strongly rejected in the Czech Republic and Hungary, when broad money is observed. This is the case because estimated Bayesian QR parameters are either negative or close to zero. On the other hand, we find positive Bayesian quantiles in the cases of Poland and Russia, and it is noticeable that these QR parameters are slightly higher than in the case when narrow money is observed. Due to the very similar results when M1 and M3 aggregates are observed, adds to the robustness of the overall findings. It can be seen that the size of the spillover effect grows with the increase of the time-horizons in both countries, but this link never riches the perfect correlation as QTM predicts. 
Figure 6

Plots of the Estimated Bayesian QR Parameters - The Transmission from M3 to Inflation
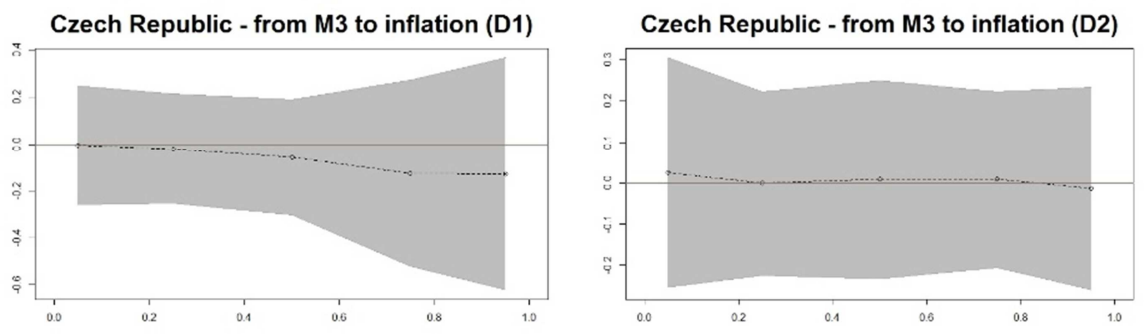

Czech Republic - from M3 to inflation (D3)

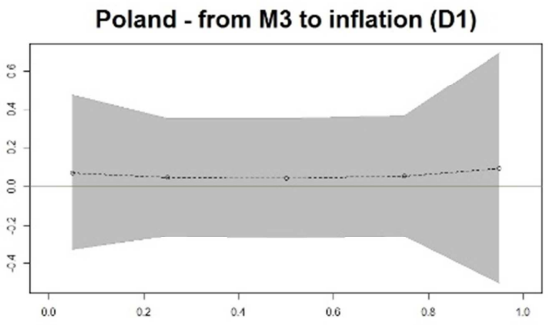

Poland - from M3 to inflation (D2)

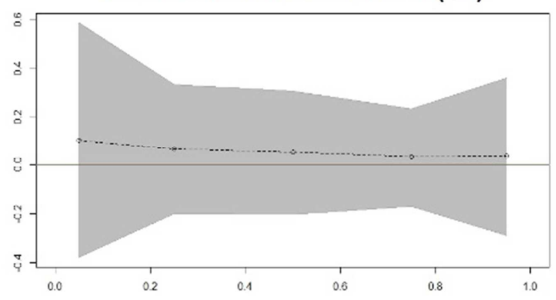

Poland - from M3 to inflation (D3)

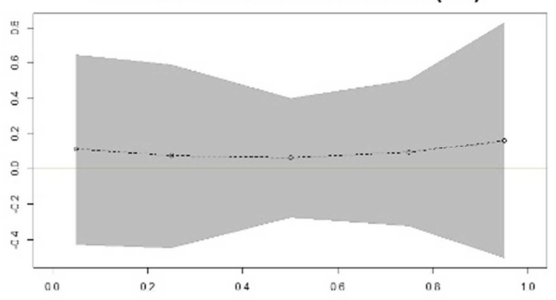

Hungary - from M3 to inflation (D1)
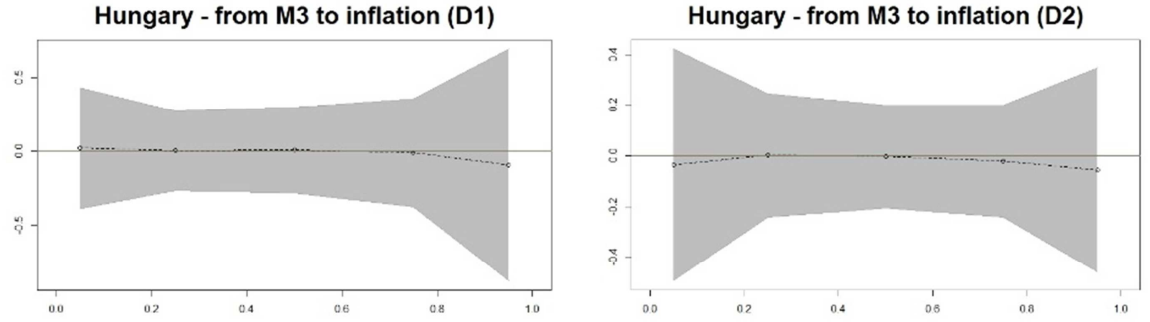

Hungary - from M3 to inflation (D3)

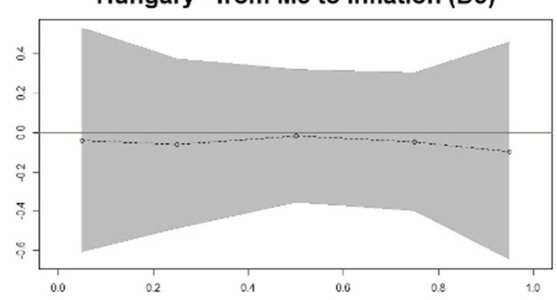

Russia - from M3 to inflation (D1)

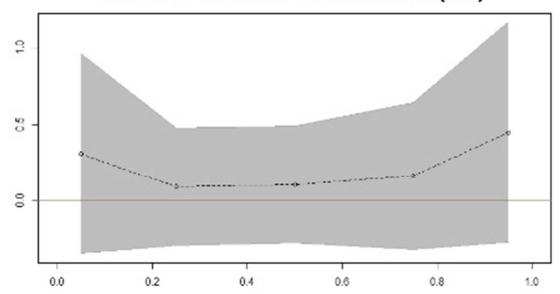



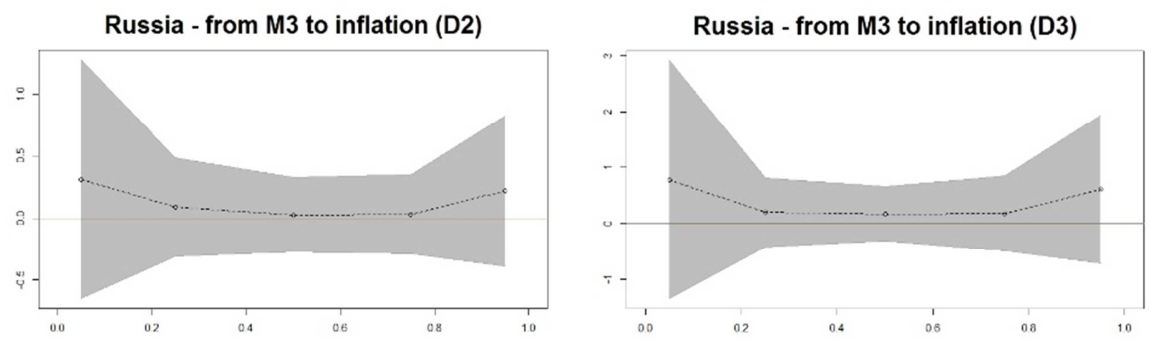

Note: The shaded area indicates credible intervals at 95 percent probability.

Source: Authors' calculation.

We find the strongest transmission effect in the tails of the distribution in the long-term horizon in both Poland and Russia. In Poland, this impact is $11 \%$ when inflation is low and $16 \%$ when inflation is high.

However, in Russia, which has not history of strict commitment to keep inflation low, we report much higher quantile parameters, comparing with the Polish counterparts. This is particularly true when Russian inflation is very low (left-tail quantile), and in these occasions, the spillover effect reaches almost $80 \%$. On the other hand, in conditions when inflation in Russia is very high, the transmission effect from broad money to inflation is $60 \%$, which is also high. We compare our results with the paper of Oomes and Ohnsorge (2005), who researched the Russian case and who asserted that an excess supply of effective broad money is inflationary, while an excess supply of narrower monetary aggregates is not. They also claimed that effective broad money growth has the strongest and most persistent effect on short-run inflation.

We have to said that our results point otherwise and disagree with the findings of Oomes and Ohnsorge (2005) in the most part. Firstly, we find that narrow money also influence inflation, as well as broad money, although this impact is slightly lower than in the case of broad money. Secondly, our results suggest that the strongest transmission effect come to the fore in the long-term, and not short-term horizon, taking into account both monetary aggregates. This outcome is close to the traditional QTM principle.

Therefore, the obvious discrepancy between our and their results could be explained by the difference in the applied methodologies. They used Johansen cointegration approach, which is not much elaborate method, and thus not much reliable.

On the other hand, we put an emphasis on the accurateness of the results, hence our choice is the wavelet-based Bayesian quantile regression, which is capable of producing efficient and statistically significant estimates, since this method uses MCMC algorithm. 


\section{Conclusion}

This study investigates how excessive money growth affects inflation in the four CEEC (the Czech Republic, Poland, Hungary and Russia), i.e. we investigate whether postulates of the traditional QTM hold. We test this theory in different time-horizons, applying wavelet signal decomposing technique. Also, we want to obtain precise measures of money impact on inflation in different market condition, that is, in conditions when inflation is low, moderate or high. For that purpose, we use Bayesian quantile regression approach, which can yield exact and efficient quantile estimates. In addition, we test whether inflation targeting implementation plays a role in curbing inflation in excessive money environment. Therefore, we intentionally select three Visegrad group countries which conducts IT nearly two decades now, and Russia, which adopted IT strategy relatively recently.

The Bayesian quantile parameters indicate that money supply growth does not influence inflation in the Czech Republic and Hungary, whatsoever, regardless of whether we observe narrow money (M1) or broad money (M3). In Poland, we find that money growth impacts inflation, but very modestly, i.e. the highest impact of narrow money is around $10 \%$ in the long-run, while the impact of broad money is around $16 \%$ in the longest time-horizon. De Mendonc (2018) offered explanation why money have some effect on inflation in Poland. She claimed that arguably the lack of commitment in Poland to target inflation could be the culprit. Therefore, unlike in the Czech Republic and Hungary, money has some influence on inflation in Poland, but this impact is relatively low and not worrying. However, in the case of Russia, the transmission effect from money to inflation is much higher, and it goes around $40 \%$ in low inflation conditions (M1 aggregate), and around 78\% also in low inflation conditions (M3 aggregate). The overall results could indicate that the adoption of IT framework, as a disinflationary strategy, proved to be successful in the Visegrad group countries. This means that regardless of the money growth level, the objective of achieving low inflation can be met and the policy can be appraised as successful. On the other hand, Russia for many years did not pay much of attention to fully-fledged disinflation policy, and as a consequence, the level of its inflation was higher, comparing to the Visegrad group countries, while the spillover effect from money to inflation was significant.

This paper offers some new and credible evidence about how the adoption of the IT regime influences the successful conduction of the monetary policy in high money supply conditions. These results could shed a new light on the question whether money play a relevant role as an inflation determinant in the selected CEEC. Therefore, monetary authorities of the selected countries could find this paper interesting. 


\section{References}

ABO-ZAID, S. - TUZEMEN, D. (2012): Inflation Targeting: A Three-decade Perspective. Journal of Policy Modeling, 34, No. 5, pp. 621 - 645. DOI: 10.1016/j.jpolmod.2011.08.004.

AHROUM, R. - ACHCHAB, B. (in press): Harvesting Islamic Risk Premium with Long-short Strategies: A Time Scale Decomposition Using the Wavelet Theory. International Journal of Finance and Economics. DOI: 10.1002/ijfe.1797.

ALTAR, M. - KUBINSCHI, M. - BARNEA, D. (2017): Measuring Financial Cycle Length and Assessing Synchronization Using Wavelets. Romanian Journal of economic forecasting, 20, No. 3, pp. $18-36$.

BABECKÝ, J. - CORICELLI, F. - HORVÁTH, R. (2009): Assessing Inflation Persistence: Micro Evidence on an Inflation Targeting Economy. Finance a úvěr - Czech Journal of Economics and Finance, 59, No. 2, pp. $102-127$.

BARANOWSKI, P. - MALACZEWSKI, M. (2016): Inflation in Poland under State-dependent Pricing. Ekonomický časopis/Journal of Economics, 64, No. 10, pp. 937 - 957.

BARUNIK, J. - VACHA, L. (2013): Contagion among Central and Eastern European Stock Markets during the Financial Crisis. Finance a úvěr - Czech Journal of Economics and Finance, 63, No. 5 , pp. $443-453$.

BAXA, J. - PLAŠIL, M. - VAŠ́́ǏCKK, B. (2015): Changes in Inflation Dynamics under Inflation Targeting? Evidence from Central European Countries. Economic Modelling, 44, No. C, pp. 116 - 130. DOI: 10.1016/j.econmod.2014.10.028.

BENOIT, D. F. - van den POEL, D. (2012): Binary Quantile Regression: A Bayesian Approach Based on the Asymmetric Laplace Distribution. Journal of Applied Econometrics, 27, No. 7, pp. 1174 - 1188. DOI: $10.1002 /$ jae.1216.

BENOIT, D. F. - van den POEL, D. (2017): BayesQR: A Bayesian Approach to Quantile Regression. Journal of Statistical Software, 76, No. 7, pp. 1 - 32. DOI: 10.18637/jss.v076.i07.

BLINDER, A. S. - EHRMANN, M. - FRATZSCHER, M. - HAAN, J. D. - JANSEN, D.-J. (2008): Central Bank Communication and Monetary Policy: A Survey of Theory and Evidence. Journal of Economic Literature, 46, No. 4, pp. 910 - 945. DOI: 10.1257/jel.46.4.910.

BUDINA, N. - MALISZEWSKI, W. - de MENIL, G. - TURLEA, G. (2006): Money, Inflation and Output in Romania,1992 - 2000. Journal of International Money and Finance, 25, No. 2, pp. 330 - 347. DOI: 10.1016/j.jimonfin.2005.11.006.

CANOVA, F. - MENZ, T. (2010): Japan's Lost Decade: Does Money Have a Role? Journal of the Japanese and International Economies, 24, No. 2, pp. 178 - 195. DOI: 10.1016/j.jjie.2009.12.001.

DAJČMAN, S. (2012): The Dynamics of Return Comovement and Spillovers between the Czech and European Stock Markets in the Period 1997 - 2010. Finance a úvěr - Czech Journal of Economics and Finance, 62, No. 4, pp. $368-390$.

De GRAUWE, P. - POLAN, M. (2005): Is Inflation Always and Everywhere a Monetary Phenomenon? Scandinavian Journal of Economics, 107, No. 2, pp. 239 - 259. DOI: $10.1111 / \mathrm{j} .1467-9442.2005 .00406 . x$.

de MENDONC, H. F. (2018): Credibility and Inflation Expectations: What We can Tell from Seven Emerging Economies? Journal of Policy Modeling, 40, No. 6, pp. 1165 - 1181. DOI: $10.1016 / j . j p o l m o d .2018 .06 .001$.

DEWANDARU, G. - RIZVI, S. A. R. - MASIH, R. - MASIH, M. - ALHABSHI, S. O. (2014): Stock Market Co-movements: Islamic versus Conventional Equity Indices with Multi-timescales Analysis. Economic Systems, 38, No. 4, pp. 553 - 571. DOI: 10.1016/j.ecosys.2014.05.003.

DUCZYNSKI, P. (2005): On the Empirics of the Non-neutrality of Money: Evidence from Developed Countries. Finance a úvěr - Czech Journal of Economics and Finance, 55, No. 5 - 6, pp. 267 - 282. 
DYBCZAK, K. - GALUŠČÁK, K. (2013): Changes in the Czech Wage Structure: Does Immigration Matter? Finance a úvěr - Czech Journal of Economics and Finance, 63, No. 2, pp. 108 - 128.

ERDÖS, T. (2008): Inflation Targeting in Hungary: A Case Study. Acta Oeconomica, 58, No. 1, pp. 29 - 59. DOI: 10.1556/aoecon.58.2008.1.2.

FRIEDMAN, M. (1968): The Role of Monetary Policy. American Economic Review, 58, No. 1, pp. $1-17$.

GAJEWSKI, P. (2018): Patterns of Regional Inflation Persistence in a C.E.E. Country. The Case of Poland. Economic Research - Ekonomska Istraživanja, 31, No. 1, pp. 1351 - 1366. DOI: $10.1080 / 1331677 X .2018 .1484789$.

HALL, S. G. - HONDROYIANNIS, G. - SWAMY, P. A. V. B. - TAVLAS, G. S. (2009): Assessing the Causal Relationship between Euro Area Money and Prices in a Time-varying Environment. Economic Modelling, 26, No. 4, pp. 760 - 766. DOI: 10.1016/j.econmod.2008.07.007.

HE, Q. - XU, L. - MEN, Y. (2020): Composition Effect Matters: Decomposing the Gender Pay Gap in Chinese University Graduates. Economic Research - Ekonomska Istraživanja, 31, No. 1, pp. 847 - 864. DOI: 10.1080/1331677X.2020.1734850.

HORVATH, R. (2008): Undershooting of the Inflation Target in the Czech Republic: The Role of Inflation Expectations. Finance a úvěr - Czech Journal of Economics and Finance, 58, No. 9 - 10, pp. $482-492$.

HORVATH, R. - KOMAREK, L. - ROZSYPAL, F. (2011): Does Money Help Predict Inflation? An Empirical Assessment for Central Europe. Economic Systems, 35, No. 4, pp. 523 - 536. DOI: $10.1016 /$ j.ecosys.2011.03.001.

IMF World Economic Outlook Database (2019). Available at: <www.data.imf.org/>.

KOENKER, R. - BASSETT, G. (1978): Regression Quantiles. Econometrica, 46, No. 1, pp. 33 - 50.

KOENKER, R. - MACHADO, J. A. F. (1999): Goodness of Fit and Related Inference Processes for Quantile Regression. Journal of the American Statistical Association, 94, No. 448, pp. 1296 - 1310. DOI: 10.1080/01621459.1999.10473882.

KUČEROVÁ, Z. - POMĚNKOVÁ, J. (2015): Financial and Trade Integration of Selected EU Regions: Dynamic Correlation and Wavelet Approach. Ekonomický časopis/Journal of Economics, 63, No. 7, $686-704$.

LEE, C. M. - LEE, H. S. (2016): Improving the Predictive Power of Spreads for Economic Activity: A Wavelet Method. Romanian Journal of Economic Forecasting, 19, No. 4, pp. 65 - 78.

MADALENO, M. - PINHO, C. (2012): International Stock Market Indices Comovements: A New Look. International Journal of Finance and Economics, 17, No. 1, pp. $89-102$. DOI: $10.1002 /$ ijfe.448.

MAESTRI, V. (2013): Imputed Rent and Distributional Effect of Housing-related Policies in Estonia, Italy and the United Kingdom. Baltic Journal of Economics, 13, No. 2, pp. 37 - 60. DOI: $10.1080 / 1406099 x .2013 .10840532$.

MAKIN, A. J. - ROBSON, A. - RATNASIRI, S. (2017): Missing Money Found Causing Australia's Inflation. Economic Modelling, 66, No. C, pp. 156 - 162. DOI: 10.1016/j.econmod.2017.06.009.

NELSON, E. (2008): Why Money Growth Determines Inflation in the Long Run: Answering The Woodford Critique. Journal of Money, Credit and Banking, 40, No. 8, pp. 1791 - 1814. DOI: 10.1111/j.1538-4616.2008.00183.x.

NIKKINEN, J. - PYNNÖNEN, S. - RANTA, M. - VÄHÄMAA, S. (2011): Cross-dynamics of Exchange Rate Expectations: A Wavelet Analysis International Journal of Finance and Economics, 16, No. 3, pp. 205 - 217. DOI: 10.1002/ijfe.423.

OECD Statistics (2019). Available at: <https://stats.oecd.org/>.

OOMES, N. - OHNSORGE, F. (2005): Money Demand and Inflation in Dollarized Economies: The Case of Russia. Journal of Comparative Economics, 33, No. 3, pp. $462-483$. DOI: 10.1016/j.jce.2005.05.007.

OUYANG, A. Y. - RAJAN, R. S. (2019): The Impact of Financial Development on the Effectiveness of Inflation Targeting in Developing Economies. Japan and the World Economy, 50, No. C, pp. 25 - 35. DOI: 10.1016/j.japwor.2019.03.003. 
PAUL, S. - RATHER, S. R. - RAMACHANDRAN, M. (2017): Money and Inflation in India: Evidence from P-star Model. Bulletin of Economic Research, 69, No. 4, pp. E94 - E111. DOI: $10.1111 /$ boer.12104.

PIGOU, A. C. (1951): The Value of Money. Quarterly Journal of Economics, 32, pp. 1917 - 1918.

RUA, A. (2012): Money Growth and Inflation in the Euro Area: A Time-frequency View. Oxford Bulletin of Economics and Statistics, 74, No. 6, pp. 875 - 885. DOI: 10.1111/j.1468-0084.2011.00680.x.

SRIRAM, K. - RAMAMOORTHI, R. V. - GHOSH, P. (2013): Posterior Consistency of Bayesian Quantile Regression Based on the Misspecified Asymmetric Laplace Density. Bayesian Analysis, 8, No. 2, pp. 489 - 504. DOI: 10.1214/13-ba817.

SU, C.-W. - FAN, J.-J. - CHANG, H.-L. - LI, X.-L. (2016): Is there Causal Relationship between Money Supply Growth and Inflation in China? Evidence from Quantity Theory of Money. Review of Development Economics, 20, No. 3, pp. 702 - 719. DOI: 10.1111/rode.12194.

TELATAR, E. - CAVUSOGLU, T. (2005): Long-run Monetary Neutrality: Evidence from High Inflation Countries. Ekonomický časopis/Journal of Economics, 53, No. 9, pp. 895 - 910.

THORNTON, J. (2008): Money, Output and Inflation in African Economies. South African Journal of Economics, 76, No. 3, pp. 356 - 366. DOI: 10.1111/j.1813-6982.2008.00199.x.

VILERTS, K. (2018): The Public-private Sector Wage Gap in Latvia. Baltic Journal of Economics, 18, No. 1, pp. 25 - 50. DOI: 10.1080/1406099x.2018.1457356.

WANG, R. - LI, L. (2020): Dynamic Relationship between the Stock Market and Macroeconomy in China (1995 - 2018): New Evidence from the Continuous Wavelet Analysis. Economic Research - Ekonomska Istraživanja, 33, No. 1, pp. $521-539$. DOI: 10.1080/1331677X.2020.1716264.

YU, K. - ZHANG, J. (2005): A Three-parameter Asymmetric Laplace Distribution and its Extension. Communications in Statistics: Theory and Methods, 34, No. $9-10$, pp. $1636-1640$. DOI: 10.1080/03610920500199018.

YU, K. - MOYEED, R. A. (2001): Bayesian Quantile Regression. Statistics and Probability Letters, 54, No. 4, pp. 437 - 447. DOI: 10.1016/s0167-7152(01)00124-9.

ŽIVKOV, D. - BALABAN, S. - ĐURAŠKOVIĆ, J. (2018): What Multiscale Approach can Tell about the Nexus between Exchange Rate and Stocks in the Major Emerging Markets? Finance a úvěr - Czech Journal of Economics and Finance, 68, No. 5, pp. 491 - 512.

ŽIVKOV, D. - MANIĆ, S. - ĐURAŠKOVIĆ, J. (2019): Multiscale Volatility Transmission and Portfolio Construction between the Baltic Stock Markets. Finance a úvěr - Czech Journal of Economics and Finance, 69, No. 2, pp. $211-236$. 